\title{
CONTROVERSY
}

\section{Practical concerns about the diagnosis of Munchausen syndrome by proxy}

\author{
C J Morley
}

The purpose of this paper is to share my concerns about the difficulties and pitfalls with the diagnosis of Munchausen syndrome by proxy in general and in particular with regard to suffocation.

\section{Concern about the use of the label \\ Munchausen syndrome by proxy}

Following the suggestion that Beverley Allitt had Munchausen syndrome by proxy ${ }^{1}$ this diagnosis has become charged with emotion and those who are now accused are tarnished with her reputation. The diagnosis of Munchausen syndrome by proxy gives no indication about what happened to the child. As a substitute I suggest that the exact nature of the problem should be stated: suffocation, poisoning, putting blood in the urine, falsely reporting fits, or whatever is the problem.

\section{Concern about the criteria for diagnosing Munchausen syndrome by proxy \\ It has been suggested that the term can be used if the following criteria are fulfilled. ${ }^{2}$ However, they are very non-specific and can be misinter- preted.}

THE ILLNESS IS FABRICATED BY THE PARENT OR CARER

A mother may superficially appear to the doctors to fabricate her child's symptoms when in reality they have not listened carefully to her story. Many mothers are just over anxious and trying to get the doctor to listen, or exaggeration may be part of her normal language.

THE CHILD IS PRESENTED TO DOCTORS, USUALLY PERSISTENTLY

The frequency of mothers presenting their children for medical care is not known and therefore we do not know what is normal or abnormal. Some mothers maintain their children are never ill and anxious mothers request advice almost weekly. Children who are seen frequently may genuinely be ill.

THE PERPETRATOR (INITIALLY) DENIES

CAUSING THE CHILD'S ILLNESS

The 'perpetrator' may genuinely be innocent and that is why she persistently and vehemently denies harming her child. I am concerned that in some cases the mothers are told they have to confess to harming their child before they can have treatment and if they do not confess they are unlikely to have their children back. This is blackmail and may result in a false confession from a mother desperate to get her child back. Surely help, counselling, and treatment can be started and continue without a 'confession'.

THE ILLNESS CLEARS UP WHEN THE CHILD IS SEPARATED FROM THE PERPETRATOR

The illness clearing up when the child is separated from the 'perpetrator' needs to be considered very carefully. Many childhood illnesses get better with time. Some conditions such as apnoea or vomiting improve towards the end of the first year, just about the time many of these children are taken into care. If the underlying problem is mother's anxiety the symptoms she is worried about may not be considered abnormal by a more experienced carer and disappear when the child is removed.

\section{Concern is about the 'indicators that} presenting symptoms may be fabricated' The following 'diagnostic pointers' have been recommended. ${ }^{3}$ At first glance these seem useful. However, when they are examined carefully they are very non-specific.

- Inconsistent histories from different observers The interpretation of inconsistency depends on how the history was obtained and whether the same questions were asked in the same way.

- Symptoms and signs that are unusual or bizarre and inconsistent with known pathophysiology - The interpretation of these depends on the experience of the doctor.

- Observations and investigations inconsistent with parental reports or the condition of the childThis may simply be because of the way the parent was asked to report. Some mothers are poor at giving a detailed account of a life threatening event. Rarely are they told to give a scientifically accurate report to the doctors.

- Treatments which are ineffective or poorly tolerated-This is common.

- Symptoms or signs which begin only in the presence of one parent/carer - Most concerned mothers are with their ill child all the time. It is 
not surprising that they are often the first witness.

- Parents who are unusually calm for the severity of illness - Parents who appear outwardly calm may be suffering inner turmoil.

- Parents who are unusually knowledgeable about the illness and its repercussions - This is common in concerned parents and those with a chronically ill child, particularly if they have been properly informed by the doctors.

- Parents who fit in contentedly with ward life and attention from staff-This is common when the children have been in a ward several times or where the ward is well organised and the staff caring and compassionate.

- Unusual or unexplained illness or death in previous children - It is important not to jump to conclusions but to investigate the details of the deaths or illnesses.

- Parents who have a history of unusual illness or themselves were abused as children - This needs careful history taking, scrutiny of the notes, or confidential discussion with the mother's doctors.

- Parents who have a history of conduct or eating disorders - These are relatively common in the community. Most of these people do not abuse their children.

The accuracy and predictive value of these diagnostic pointers are not known. As Munchausen syndrome by proxy is very rare these pointers are much more likely to be associated with normal behaviour and common illnesses. Unthinking use of such indicators without realising their non-specific nature may lead to mothers being falsely accused and their children taken into care.

\section{Concern about 'exaggeration' being} labelled Munchausen syndrome by proxy Munchausen syndrome by proxy is being used to describe the behaviour of mothers who exaggerate a child's symptoms. This is a cause for concern because mothers frequently exaggerate their child's symptoms, not through any malignant desire to mislead the doctor but as part of common language: 'he hasn't eaten a thing all week', 'he vomits up all the feed'. Such phrases are part of everyday life and experienced paediatricians do not take the mother's story at face value but take a careful history to find out exactly what has been happening. We have no idea how common it is for mothers to exaggerate their children's symptoms. If exaggeration is included in Munchausen syndrome by proxy this will devalue the diagnosis and more mothers will be accused.

\section{Concern about inadequate history taking}

Diagnosing Munchausen syndrome by proxy is very serious because the outcome for the child and family may mean care orders, separation, and even criminal prosecution. It is primarily a medical diagnosis and must be based on sound medical practice. This means taking a very careful history, eliciting exact details about what has happened. ${ }^{4}$ It may mean talking to the mother for hours to get a clear understanding about all the episodes, why she is concerned, and her own background. Unfortunately, in some cases, the senior doctors have hardly talked to the mother. In a recent case the mother briefly saw the consultant during the children's illnesses and he did not take time to sit down and talk with her until he came with a social worker to say she was accused of Munchausen syndrome by proxy. This is indefensible.

My experience is that some mothers repeatedly take their child to the family doctor or paediatrician because they are anxious. Some are naturally anxious; some have hypochrondia; and others are anxious because their children have previously been very ill. The doctor realises the illnesses are trivial and repeatedly tells the mother not to worry. If the doctor had taken the time, in the early part of the illness, to take a full history, to explain what was happening, understand why she was so concerned, and support the mother, he could have prevented many of the repeated presentations and the subsequent accusation of Munchausen syndrome by proxy.

\section{In conclusion}

Munchausen syndrome by proxy is a term I suggest we use with caution and preferably abandon in favour of giving an exact description of what has happened to the child. It has become a diagnosis with emotional overtones which do not help in the management of these difficult cases. I do not consider that a mother exaggerating genuine symptoms or signs should be considered part of Munchausen syndrome by proxy. I urge caution about some of the criteria for this diagnosis and concern about some to the accuracy, sensitivity, and ethics of some techniques being used. I urge doctors to take detailed histories and talk to the mothers in a caring way about their concerns. It is important to protect a child who is being harmed by his mother. It is equally important not to harm the child by falsely accusing his mother of Munchausen syndrome by proxy thereby breaking up the family.

\section{The Allitt inquiry. London: HMSO, 1994. \\ 2 Meadow SR. 'Who's to blame - mothers, Munchausen or medicine?' $f R$ Coll Physicians Lond 1994; 28: 332-7. \\ 3 Samuels MP, Southall DP. Munchausen syndrome by proxy. Br f Hosp Med 1992; 47: 759-62. \\ 4 Working Party of the British Paediatric Association. Evaluation of suspected imposed upper airway obstruction. London: BPA, February 1994: 24 (section 6.2.5).}

\section{Commentary}

The concerns which Dr Morley expresses over the diagnosis of Munchausen syndrome by proxy are numerous but fall into two main area. These are the appropriateness of the label and the specificity of the criteria used in the diagnosis.

THE LABEL

There is no doubt, despite claims in the press, that Beverley Allitt did not have Munchausen 